\title{
The Culture Trade Balance during Financial Crisis the Case of Greece
}

\author{
Dr. Dapontas Dimitrios* \\ 6 filikis eterias St., 25001, Kalavryta, Greece \\ *Corresponding Author \\ Dr. Dapontas Dimitrios
}

Article History

Received: 05.08.2019

Accepted: 16.08 .2019

Published: 25.08.2019

\begin{abstract}
This work presents the relationship between the sectorial trade balance and its relationship to the financial crisis hit severe Eurozone and especially Greece. The country has a long history both on culture and economic crises introducing this term in anciency. We deployed a bunch of six explanatory variables related to the balance of payments especially on productivity and economic freedom terms as long with contagion and possible GNP spending applying the robust least squares analysis to an industry balance. The results show that the crisis in or at related countries seem to have positive effect and Productivity related variables have negative. Cultural spending on GDP share has also positive effect.
\end{abstract}

JEL CODES: Z 100, J 640, F 660

Keywords: Trade balance, Contagion, Sectoral GNP, Productivity, Economic Freedom.

\section{INTRODUCTION}

Present work can explain the behavior of one of the most important sectoral balance for Greece and the recent turbulence for a part of the Eurozone. Greece consisting only $2 \%$ of the European economic union has a long history in both crises and cultural international trade. Country faces a deficit on this balance which has been significantly reduced during the crisis's years and beyond. What was the role of the crisis itself and what of crises in other countries economically related to and especially Eurozone members to the past imbalance correction? How productivity expressed in terms of basic education labor production and economic freedom acted? Prices had their remedial role to the deficit? And finally, the percentage of GNP to culture to a falling amount which role had to the phenomenon? Manuscript is structured as follows: On the present part an introduction and research questions are presented. Past works related to the subject are given to the second part. The third part gives the selected model's function and selections along with the variable's characteristics. On the final part we present the results and give conclusions and possible further research proposals.

\section{Past works}

The relationship between trade balance and crisis has a long history equal to the one of financial crisis analysis. First generation models [1] but its effect to early literature is still unclear [2] deficit as stated "may matter" or weak correlation is present [3]. The major effects of balance of payments to crisis and its aftermath analyzed more significantly at the case of Asian crisis. On the long -term the effect of excess export capacity to the income is multiplying, even though initially the domestic obstacles seem to pay important role. Twin crises also make the remedy more difficult and when it comes is an effect of import compression [4]. However, in industrialized countries the domestic income share to culture raise has effect on export is mixed [5].

The economic European integration and its consequences to culture to single market has been studied to a set of early manuscripts $[6,7]$ where integration and its consequences not limited to contagion on crises or public budget have to be considered on the basis of the European Union (EU) framework. Member states benefit but also infected by the lack of a common European cultural policy. However, systemic coordination is similar among and exterior to EU as stated by later scholars [8] the channel of integration seems to be the $R \& D$, under the high scientific cooperation and business innovation level of cooperation. Scott [19] on a comparative study, he remarked the target of prohibiting illegal trade practices by protection through an extensive EU framework which seems stricter compared to similar protection networks worldwide.

Copyright @ 2019: This is an open-access article distributed under the terms of the Creative Commons Attribution license which permits unrestricted use, distribution, and reproduction in any medium for non commercial use (NonCommercial, or CC-BY-NC) provided the original author and source are credited. 
Market characteristics seem to have significant change due to integration [9] and IT technologies had also boosting impact on early 2000's reengineering the whole industry process along with public spending role from 2008 and beyond as a lender of last resort. Crisis effects have disorientated the whole industry [10] and the dependent on public debt became unfortunately a major safe port for all similar and low funded activities but also the temporary character of funding could be considered as a threat. The downfall on the early crisis years (since 2009) was extremely harsh and both marketing and strategic partnership schemes become the rule. Initially they seem to have a positive effect whereas these channels weren't parallel supported by private funding which fall more than expected especially at the aboriginal turbulence period. The budget cuts seem to have negative effect on undereducated labor especially for younger culture workers or companies with a high rate of fall and closure. This new economic era had more sound effect on lower income countries among the European Union. In culture market an artistic elite was developed where self-funding high income artists not only survived but extended the gap to the citizen enrolment base where survival became a priority for them due to underfunding. Antithesis due to funding also broadened due to decline of economic and political freedom. Priorities have also transferred from personal interests or symbolic value to commercialization or targeted fundraising.

Later [11] analyzed the Greek case as a major part of the European crisis, the cultural sector is crucial to the country's economic policy facing high bureaucracy walls and economic corruption raise during crisis. Other difficulties include the high and long coming nepotism and patronage overcoming every possibility for investment. Thus, economic and political freedom seems to be low and possible recession is getting late. Magoulios and Athianos [12] claim that country had a major increase on trade budget deficit due to lack of competitive advantage on high technology and unbalances due to incomplete integration are also present.

The democratic lack expanded during crisis [13] and the fundamental cultural rights have been often breeched. The closure of one out of five public libraries in the UK was a result of public budget cut but against people will. Room of expressing new ideas is in lack but also transparency as a government's obligation. Independent and volunteer-based artists were due to the framework marginalized.

\section{METHODS AND VARIABLES USED}

Robust least squares method needs the fitting phase of selecting variables effecting culture trade balance for Greece. We have to develop a partial-correlation analysis framework among the external variables because we should avoid possible multicollinearities among independent variables but also, we have to examine and denote binary relations between them.

The nature of the under-analysis data and its relationships is so complicated that a straight effect is rarely present and conclusions cannot be made. The exact methods such as robust square analysis (RLS) are more accurate than earlier and well used and worn parametric or non-parametric methods. Accuracy on least squares methods such as robust least squares (RLS) seems is more precarious to dissentients within datasets. The RLS is an exact method selection because it's the most flexible among exact methods and accurate on placing a set within a framework of possibly related independent variables. We use EViews ${ }^{\mathrm{tm}}$ software robust least squares model as it is estimated.

The selected robustness estimation type is M-Estimation. Huber [17] states that the large residuals can lead external variables outputs out of the model framework in favor of possible exact results. The variety of extractions is generally high due to control developed on pre-stage analysis among regressors. Through this method the constant term is present and highly adjustable. The Least Squares are given by the objective function:

$$
\widehat{\beta_{L S}}=\operatorname{argmim}_{\beta} \sum_{i=1}^{N} r_{i}(\beta)^{2}
$$

Where $r$ the residuals are:

$$
r_{i}(\beta)=r_{i}=y_{i}-X_{i}^{\prime} \beta
$$

The estimated values of residuals are lessened on $\mathrm{M}$ - estimation function:

$$
\widehat{B_{M}}=\operatorname{argmin}_{\beta} \sum_{i=1}^{N} \rho_{c}\left(\frac{r_{i}(\beta)}{\sigma w_{i}}\right)
$$

Where $\sigma$ measures the mount of residuals, $c$ is the constant point related to function of equal weights $w$ and $\rho$ is the underlying function (turning constant). We have chosen Cauchy function due to $95 \%$ confidence interval and its default $c$ value (2.385).

$$
\left(\frac{c^{2}}{2}\right) \log \left(1+\left(\frac{X}{c}\right)^{2}\right)
$$


The R- squared given by Maronna, Marin and Yohai [18] are:

Where $\tilde{\mu}$ is the $\mathrm{M}$ - estimation as specified by constant only.

$$
R^{2}=\frac{\sum_{i=1}^{N} \rho_{c}\left(\frac{y_{i}-\tilde{\mu}}{\hat{\sigma} w_{i}}\right)-\sum_{i=1}^{N} \rho_{c}\left(\frac{r_{i}}{\hat{\sigma} w_{i}}\right)}{\sum_{i=1}^{N} \rho_{c}\left(\frac{y_{i}-\tilde{\mu}}{\hat{\sigma} w_{i}}\right)}
$$

A set of variables connecting trade balance on culture (dependent variable) and the economic and financial crisis and possible factors affecting the under-examination variable. The choice is under the light of eliminating possible collinearities among the regressors. The frequency is annual due to the nature of the variables thus there is no seasonality among them.

Cultural Trade Balance: Is the difference on the balance between cultural exports and cultural imports in a country given by Eurostat and UNESCO data provided. Greece has a cultural balance deficit for all the years but it has been significantly declined during the last years where the amount and the value of imports have been reduced. The variables that could affect this conduct are presented below.

Basic Education Labor: Is the percentage of basic education workers holding a job given by IMF Statistics. This variable can be considered a measure of productivity. If productivity is high then people with lower skills can also reach the labor market easier. The low productivity of a country means that this access will have difficulties rising over time in every sector of the economy. Higher education people could find a job easier due to their skills. In this case the reduction of this class participation on workforce is a sign of productivity decline. Thus, we expect a negative sign.

$\mathrm{CPI}$ on culture: The yearly change of CPI related to the cultural products. It is a macroeconomic stability analysis variable related to the price level change over time with a negative impact related to the economy's instability over time. Possible effect related to traditional economic theory under Philips curve seems to be positive to be but related to post Keysian theory the effect seems to be in reverse. In some practical cases though $[14,15]$ it can be a pain in the back for country's exports making them more expensive and less attractive.

Basic Education Labor: Is the percentage of basic education workers holding a job given by IMF Statistics. This variable can be considered a measure of productivity. If productivity is high then people with lower skills can also reach the labor market easier. The low productivity of a country means that this access will have difficulties rising over time in every sector of the economy. Higher education people could find a job easier due to their skills. In this case the reduction of this class participation on workforce is a sign of productivity decline. Thus we expect a negative sign.

Crisis: This binary variable taking the prices of zero ( 0 , no crisis) or one (1, crisis). Various definitions are generally given but the most of them name it as one of a kind, non-ordinary, rare event or a set of similar small-scale occurrence on the same country. The main idea has to do with the economy and its external sector. A devaluation compared to the previous month has been deployed on the primary models where speculating attacks have been also blamed for the turbulences. During the time bonded or monetary union schemes arisen. A possible percentage in the fixed currency terms is not present. Pressure indices with the same economic effects to invariable official rate were deployed. We use for the case of Greece the proposed [16] model where Greece is included to the analysis and the crisis variable is dependent. Following this model, the fixed rate can be substituted to one of the three following occasions: First we denote as crisis the decline of the real effective exchange rate over $10 \%$ on any month of the year. Second exemplification could be a rise of at least $25 \%$ on the country's basic 10 years bond rate compared to the previous month. Finally, a monthly deterioration of $25 \%$ or more on international reserves can be named as an incident. We expect that a crisis would affect positive the trade balance of a country because of imports decline following demand fall especially on the long term and possible motive on the recession and remedy period where exports are relatively cheaper and they can get a competitive advantage.

Crisis elsewhere: It's a categorical variable denoting whether is a crisis on a related to the under-examination economy country which can be under crisis (1) or not (0) based on criteria given on the domestic crisis definition. The phenomenon was made known as "butterfly effect" spreading the turbulence to other countries. Major counterpart relationship can be denoted as a considerable candidate for transmitting the effect. The possible trade balance effect on culture industry where countries interact both as competitors and complements is questionable. It can be both positive transferring when international market participants believe that the connected country will not be affected and it could be a successful partner and negative when an escalation from effecting country is made to the national industry considering both as untrustful. The sequences of the contagion are faster and higher on the last years when a country could infect faster (no more than two months) and multiple (not only one on the same incident) [16].

$\mathrm{CPI}$ on culture: The yearly change of $\mathrm{CPI}$ related to the cultural products. It is a macro economic stability analysis variable related to the price level change over time with a negative impact related to the economy's instability over time. Possible effect related to traditional economic theory under Philips curve seems to be positive to be but related to post keysian theory the effect seems to be in reverse. 
Economic Freedom: The rate of economic freedom is issued by Heritage foundation for every country in a yearly basis, comprising various indices related to the level of freedom in every aspect of economic life. Under a strict framework a high level of freedom on a country market fragment can lead to externality on economic and satisfaction terms. This could be in favor of possible exports but higher freedom is a sign of an open market friendly to possible imports. In some cases, also national producers prefer to promote intra-trade on their favor. Consumers are free to select among a variety of national or international choices. An economy can profit from an increase of this index in multiple ways related but not limited to better confrontation of turbulences, successful participation to commercial and monetary unions, more flexible markets etc. We expect though a negative sign.

GDP \% expenditure to "recreation, culture and religion" industry: Variable is the percentage of GDP related to these sectors both individual and public which can be summarized as culture on an annual frequency provided by national authority Greek ELSTAT branch to the Eurostat. The higher percentage of GDP related to the sector is normal to make national production relatively cheaper making industry more attractive as an export industry. The spending part though is also present. Where improvement on terms of trade can be seen as investment for the national economy even though sometimes the low taxation policy implied by countries can have the opposite effect. The long-term effect will be mounting debt, lower productivity and inefficiency. On the short term however, the short-term exports are expected to rise. Thus, we expect positive relationship between the two variables.

\section{RESULTS}

The results are shown on the table below

Table-1: The RLS Results Fewer than $5 \%$ Significance

\begin{tabular}{|c|c|}
\hline C & $23,808.42(0.0000)$ \\
\hline BAS_LABOR & $-42,666,573(0.0000)$ \\
\hline CPI & $13,390,540(0.0000)$ \\
\hline CRISIS & $891,445,852(0.0000)$ \\
\hline CRISIS_E & $2,909.07(0.0000)$ \\
\hline GDP_CULT & $24,232.56(0.0000)$ \\
\hline ECO_FREE & $-21,904,694(0.0000)$ \\
\hline $\mathbf{R}^{2}$ & $0.8773(0.0000)$ \\
\hline
\end{tabular}

As we can see three variables (GDP percentage on culture, Crisis and Crisis elsewhere respectively) seem to be important and have the expected positive sign. As GDP on culture as percentage raises more money are given to the industry motivating national producers to increase the supply abroad. Crisis in Greece is also important and positive as expected. The aftermath of the Greek crisis can give opportunities to the cultural market but the remedy was really harsh. Country had to suffer for more than 8 years and many of its workers had to immigrate or remained unemployed within the country. Its effect to every sector was croaking. While traditional parts of the national economy faced a decline of 50-60\% on their annual turnover the effect on culture was less severe but it existed and mattered especially through the early years. The imports of cultural products due to lack of demand also declined rapidly. Possible low quality and cost products were imported. The variable crisis elsewhere is also important and positive. Depending on binational or international relations it could have positive if the country is based on its national cultural heritage production or consumption compared to the under-crisis economy and vice versa it could be seen as the country that could be infected next as a following victim. In our case though Greece seem to get involved on contagion crisis related to its economy and possible effects especially on import reduction over time. Similar to domestic an international crisis imports demand declines, the fact that this variable is significant can make the active part of the international political or economic crisis effects having its own possible route to the market.

Two variables (Basic education labor and Economic Freedom) both related to productivity seem to be significant. Basic education labor has declined during crisis and it was the major victim of the workforce as time passed by. This class productivity for the country seems to be lowered in every sector compared to other countries. Economic freedom and its high effect to every aspect of the market as presented and its decline during the crisis on both private and public sector has effect on industry's productivity. The more stable and developed economic environment can attract raised investment on the cultural sector based on comparison between Greece and its competitors to the cultural and touristic industry. The possible prefer to international products and intra-trade in higher freedom periods raises deficit. The constant variable can consist of possible negative factors mostly related to crisis or political and country risk compared to culturally based economies having bigger chunks of their national product and less effects of the eurozone economic turbulence. R-square seems to be high relating the important variables to the cultural employment.

Finally, Cultural CPI seems to be unimportant. This variable didn't initially seem to have a standard effect on economy. Trade balance deficit has a clear positive relation to price raise. That can be explained of the nature of the cultural products where their price effect is different to the other goods. It seems to be less important than other related factors. 


\section{Conclusion, Discussion And Further Research Suggestions}

On the present work we have seen the relationship between culture trade balance, financial and economic crisis on national mainly and on trade partnering countries secondly. On the same light we have analyzed possible variables that could affect the deficit which is present to the under examination variable. The results show that both national and external crises have positive effect on trade balance. The demand for imports in the industry declines on value as crisis arises. Less and more economic imports become an opportunity for national producers to improve their international position and the country as whole. As denoted a possible public budget raise could have a positive effect on exports. National goods that can be exported can decline a possible shortfall even though this remedy is temporary. Productivity related variables seem to have negative effect. Basic education labor which can be an indicator for the workforce enrollment has declined during time. Economic freedom allows more intra-trade and imports have also negative effect on country's deficit. Price level in the industry didn't have any effect on the Greek case as given.

In a future work a researcher could add possible effects of the currency crisis itself. Under the Euro scheme there is no national currency volatility for EMU members. Other measures related to the exchange rate itself can be investigated such as possible international reserves decline or lending interest rate spread raise in short time period can be named as a possible incident. The findings could also be compared to other countries using the channel of political risk among the countries. The discussion over the determinants of possible culture trade balance has now entered in the center of economic analysis related to the civilization and fruitful research proposals can be made.

\section{REFERENCES}

1. Krugman, P. (1979). A model of balance-of-payments crises. Journal of money, credit and banking, 11(3), 311-325.

2. Edwards, S. (2002). Does the current account matter?. In Preventing currency crises in emerging markets (pp. 21-76). University of Chicago Press.

3. Sasin, M. J. (2001). Predicting currency crises, the ultimate significance of macroeconomic fundamentals in linear specifications with nonlinear extensions. CASE Network Studies and Analyses, (224).

4. Sugema, I. (2005). The determinants of trade balance and adjustment to the crisis in Indonesia. Adelaide: Centre for International Economic Studies, University of Adelaide.

5. Falk, M. (2008). Determinants of the trade balance in industrialized countries (No. 013). FIW Research Reports.

6. Leyedesdorff, L. (1992). The impact of EC science policies on the transnational publication system. Technology Analysis and Strategic Management, 4, 279-279.

7. Luukkonen, T. (1998). The difficulties in assessing the impact of EU framework programmes. Research Policy, 27(6), 599-610.

8. Frenken, K., \& Leydesdorff, L. (2004). Scientometrics and the evaluation of European integration. Innovation, entrepreneurship and culture: The interaction between technology, progress and economic growth, 87-102.

9. Throsby, D. (1994). The production and consumption of the arts: A view of cultural economics. Journal of economic literature, 32(1), 1-29.

10. Bonet, L., \& Donato, F. (2011). The financial crisis and its impact on the current models of governance and management of the cultural sector in Europe. ENCATC Journal of cultural management and policy, 1(1), 4-11.

11. Herzfeld, M. (2013). The E uropean Crisis and Cultural Intimacy. Studies in Ethnicity and nationalism, 13(3), 491-497.

12. Magoulios, G., \& Stergios, A. (2013). The trade balance of Greece in the euro era. South-Eastern Europe Journal of Economics, 2, 187-216.

13. Pavic, K. (2016), 'New models of governance of culture', Eurozone, April $26^{\text {th }} 2016$.

14. Stucka, T. (2004). The effects of exchange rate change on the trade balance in Croatia (No. 4-65). International Monetary Fund.

15. Ahmed, R. R., Ghauri, S. P., Vveinhardt, J., \& Streimikiene, D. (2018). An Empirical Analysis of Export, Import, and Inflation: A Case of Pakistan. Romanian Journal of Economic Forecasting, 21(3).

16. Dapontas, D. (2013). Examining Eurozone Crisis and Unemployment Relationship Using Var Models. Annals of the Alexandru loan Cuza University-Economics, 60(2), 85-92.

17. Huber, P. J. (1973). Robust regression: asymptotics, conjectures and Monte Carlo. The Annals of Statistics, 1(5), 799-821.

18. Maronna, R. A., Martin, R. D., Yohai, V. J., \& Salibián-Barrera, M. (2019). Robust statistics: theory and methods (with R). John Wiley \& Sons.

19. Scott, R. M. G. (2016). The European Union's Approach to Trade Restrictions on Cultural Property: A Trendsetter for the Protection of Cultural Property in Other Regions?. Santander Art and Culture Law Review, 2(2), 211-236. 